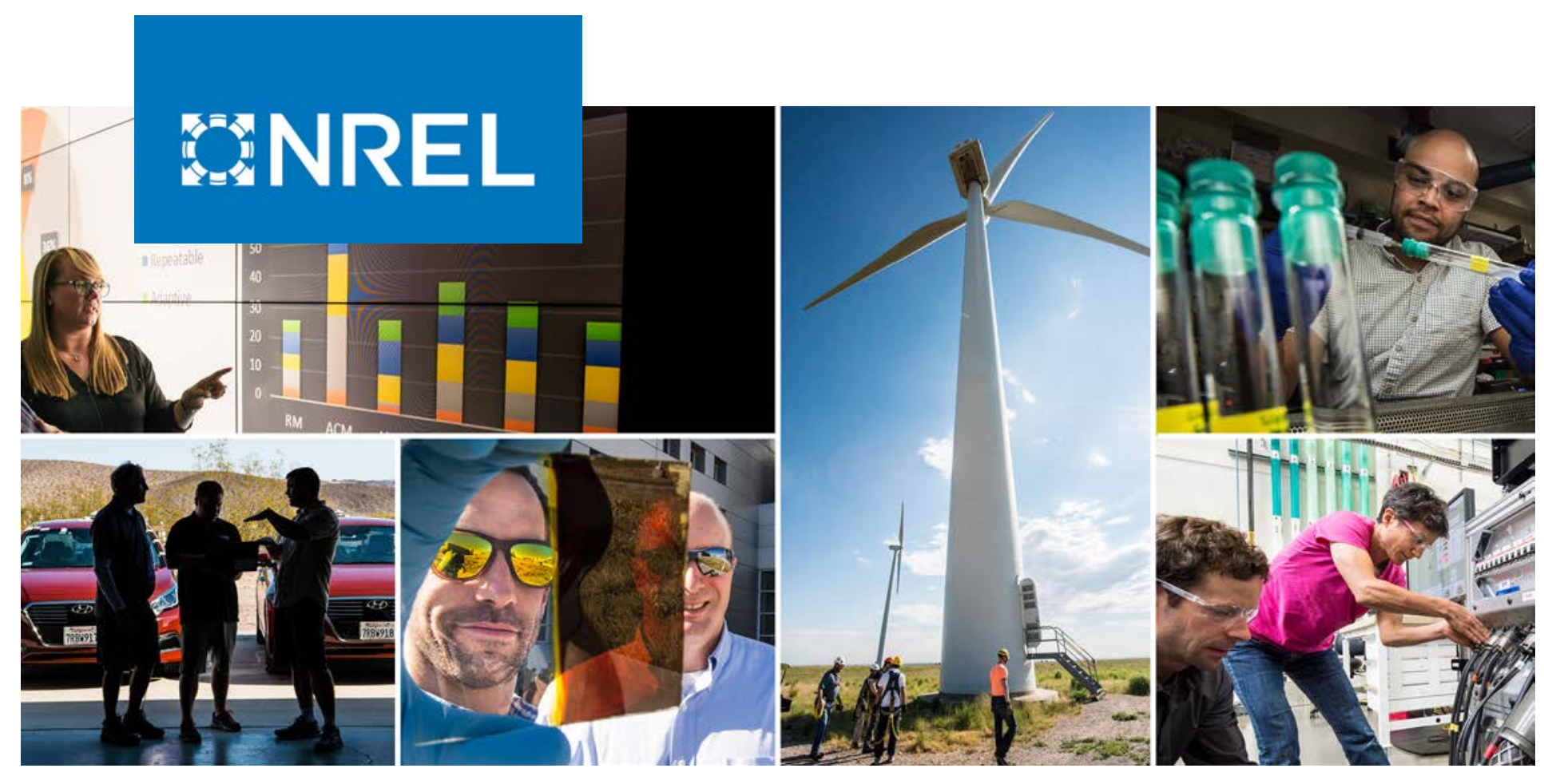

\title{
Cost Projections for Utility-Scale Battery Storage: 2020 Update
}

Wesley Cole and A. Will Frazier

National Renewable Energy Laboratory

NREL is a national laboratory of the U.S. Department of Energy

Office of Energy Efficiency \& Renewable Energy

Operated by the Alliance for Sustainable Energy, LLC

This report is available at no cost from the National Renewable Energy Laboratory (NREL) at www.nrel.gov/publications.
Technical Report

NREL/TP-6A20-75385

June 2020 


\title{
GNREL
}

\section{Cost Projections for Utility-Scale Battery Storage: 2020 Update}

\author{
Wesley Cole and A. Will Frazier
}

National Renewable Energy Laboratory

\section{Suggested Citation}

Cole, Wesley, and A. Will Frazier. 2020. Cost Projections for Utility-Scale Battery Storage:

2020 Update. Golden, CO: National Renewable Energy Laboratory.

NREL/TP-6A20-75385. https://www.nrel.gov/docs/fy20osti/75385.pdf

NREL is a national laboratory of the U.S. Department of Energy Office of Energy Efficiency \& Renewable Energy Operated by the Alliance for Sustainable Energy, LLC

This report is available at no cost from the National Renewable Energy Laboratory (NREL) at www.nrel.gov/publications.

Contract No. DE-AC36-08GO28308
Technical Report

NREL/TP-6A20-75385

June 2020

National Renewable Energy Laboratory 15013 Denver West Parkway Golden, CO 80401

303-275-3000 • www.nrel.gov 


\section{NOTICE}

This work was authored by the National Renewable Energy Laboratory, operated by Alliance for Sustainable Energy, LLC, for the U.S. Department of Energy (DOE) under Contract No. DE-AC36-08GO28308. Funding provided by the U.S. Department of Energy Office of Energy Efficiency and Renewable Energy Solar Energy Technologies Office. The views expressed herein do not necessarily represent the views of the DOE or the U.S. Government.

This report is available at no cost from the National Renewable Energy Laboratory (NREL) at www.nrel.gov/publications.

U.S. Department of Energy (DOE) reports produced after 1991 and a growing number of pre-1991 documents are available free via www.OSTI.gov.

Cover Photos by Dennis Schroeder: (clockwise, left to right) NREL 51934, NREL 45897, NREL 42160, NREL 45891, NREL 48097, NREL 46526.

NREL prints on paper that contains recycled content. 


\section{Acknowledgments}

We are grateful to ReEDS modeling team for their input on this work. We also thank David Feldman (NREL), Ryan Hledik (Brattle), Cara Marcy (EPA), Vignesh Ramasamy (NREL), and Daniel Steinberg (NREL) for providing input and feedback on this report. This report was jointly funded by the EERE Office of Strategic Programs, Solar Energy Technologies Office, Water Power Technology Office, and Wind Energy Technology Office, under contract number DEAC36-08GO28308. All errors and omissions are the sole responsibility of the authors. 


\section{Executive Summary}

In this work we describe the development of cost and performance projections for utility-scale lithium-ion battery systems, with a focus on 4-hour duration systems. The projections are developed from an analysis of 19 publications that consider utility-scale storage costs. The suite of publications demonstrates varied cost reductions for battery storage over time. Figure ES-1 shows the low, mid, and high cost projections developed in this work (on a normalized basis) relative to the published values. Figure ES-2 shows the overall capital cost for a 4-hour battery system based on those projections, with storage costs of $\$ 144 / \mathrm{kWh}, \$ 208 / \mathrm{kWh}$, and $\$ 293 / \mathrm{kWh}$ in 2030 and $\$ 88 / \mathrm{kWh}, \$ 156 / \mathrm{kWh}$, and $\$ 219 / \mathrm{kWh}$ in 2050 . Battery variable operations and maintenance costs, lifetimes, and efficiencies are also discussed, with recommended values selected based on the publications surveyed.

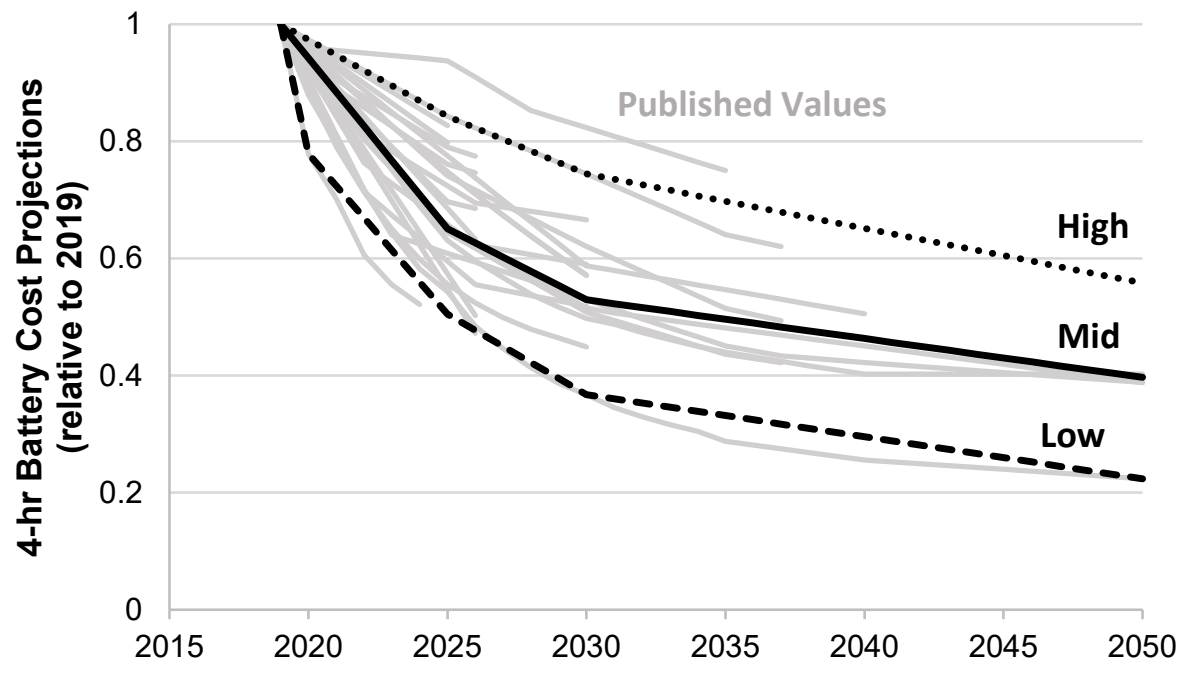

Figure ES-1. Battery cost projections for 4-hour lithium-ion systems, with values relative to 2019. The high, mid, and low cost projections developed in this work are shown as the bolded lines.

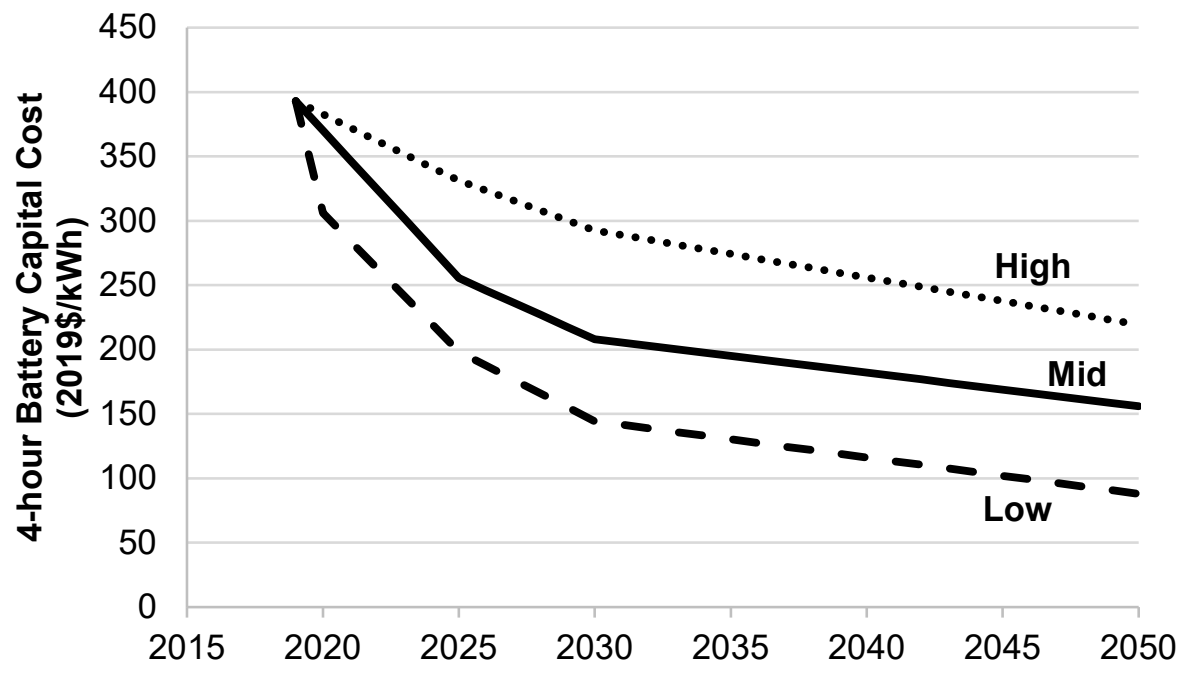

Figure ES-2. Battery cost projections for 4-hour lithium ion systems. 


\section{Table of Contents}

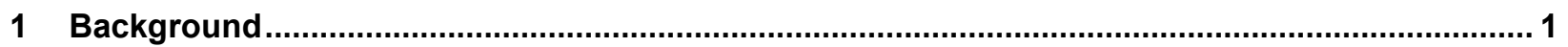

2 Methods .............................................................................................................................. 1

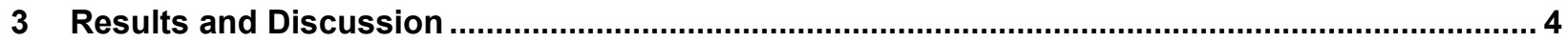

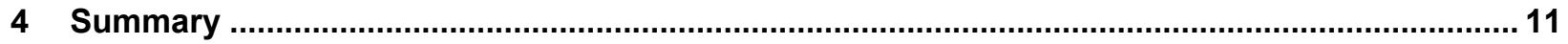

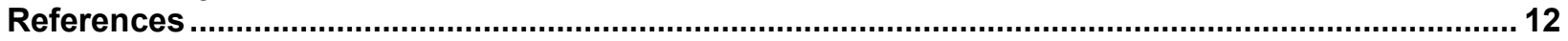

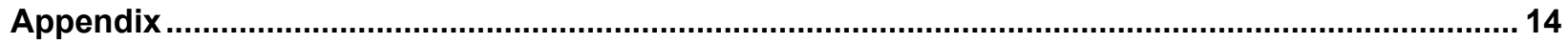

\section{List of Figures}

Figure ES-1. Battery cost projections for 4-hour lithium-ion systems, with values relative to 2019.......... iv

Figure ES-2. Battery cost projections for 4-hour lithium ion systems................................................... iv

Figure 1. Battery cost projections for 4-hour lithium-ion systems, with values relative to 2019 ................ 5

Figure 2. Battery cost projections for 4-hour lithium ion systems............................................... 6

Figure 3. Battery cost projections developed in this work (bolded lines) relative to published cost

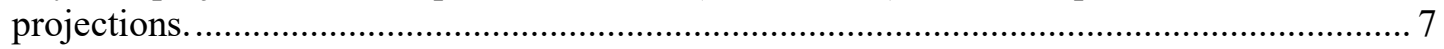

Figure 4. Current battery storage costs from studies published in 2018 or later...................................... 8

Figure 5. Cost projections for power (left) and energy (right) components of lithium-ion systems............ 9

Figure 6. Cost projections for 2-, 4-, and 6-hour duration batteries using the mid cost projection. ............ 9

Figure 8. Comparison of cost projections developed in this report (solid lines) against the values from the 2019 cost projection report (Cole and Frazier 2019) (dashed lines).................................... 15

Figure 9. Comparison of cost projections developed in this report (solid lines) the values from the 2019 cost projection report (Cole and Frazier 2019) (dashed lines), with all values normalized to the "Mid" cost projection in the year 2019.

\section{List of Tables}

Table 1. List of publications used in this study to determine battery cost and performance projections. .... 1 Table 2. Values from Figure 1 and Figure 2, which show the normalized and absolute storage costs over time. Storage costs are overnight capital costs for a complete 4-hour battery system. 


\section{Background}

Battery storage costs have changed rapidly over the past decade. In 2016, the National Renewable Energy Laboratory (NREL) published a set of cost projections for utility-scale lithium-ion batteries (Cole et al. 2016). Those 2016 projections relied heavily on electric vehicle battery projections because utility-scale battery projections were largely unavailable for durations longer than 30 minutes. In 2019, battery cost projections were updated based on publications that focused on utility-scale battery systems (Cole and Frazier 2019). This report updates the cost projections published in 2019.

The projections in this work focus on utility-scale lithium-ion battery systems for use in capacity expansion models. NREL utilizes the Regional Energy Deployment System (ReEDS) (Cohen et al. 2019) and the Resource Planning Model (RPM) (Mai et al. 2013) for capacity expansion modeling, and the battery cost projections developed here are designed to be used in those models. Additionally, the projections are intended to inform the cost projections published in the Annual Technology Baseline (NREL 2019).

\section{Methods}

The cost and performance projections developed in this work use a literature-based approach in which projections are generally based on the low, median, and highest values from the literature. Table 1 lists 19 publications that are used in this work, though the projections rely primarily on those published in 2018 or 2019.

Table 1. List of publications used in this study to determine battery cost and performance projections.

\begin{tabular}{ll} 
Author or Organization & Citation \\
\hline Avista & Avista (2017) \\
\hline BNEF & BNEF (2019) \\
\hline Brattle & Hledik et al. (2018) \\
\hline CAISO & Energy and Environmental Economics, Inc. (2017) \\
\hline DNV GL & DNV GL (2017) \\
\hline EIA & EIA (2020) \\
\hline EPRI & EPRI (2018) \\
\hline IEA & IEA (2019) \\
\hline IRENA & IRENA (2017) \\
\hline Lazard & Lazard (2018) and Lazard (2019) \\
\hline Navigant & Navigant (2017) \\
\hline NIPSCO & NIPSCO (2018) \\
\hline NYSERDA & NYSERDA (2018) \\
\hline Platt River Power Authority & Aquino et al. (2017) \\
\hline PNNL & Mongird et al. (2019) \\
\hline PSE & PSE (2017) \\
\hline Schmidt et al. & Schmidt et al. (2019) \\
\hline Wood Mackenzie & Wood Mackenzie \& Energy Storage Association (2019) \\
\hline
\end{tabular}


There are a number of challenges inherent in developing cost and performance projections based on published values. First among those is that the definition of the published values is not always clear. For example, dollar year, duration, depth-of-discharge, lifetime, and O\&M are not always defined in the same way (or even defined at all) for a given set of values. As such, some of the values presented here required interpretation from the sources specified. Second, many of the published values compare their published projection against projections produced by others, and it is unclear how much the projections rely upon one-another. Thus, if one projection is used to inform another, that projection might artificially bias our results (toward that particular projection) more than others. Third, because of the relatively limited dataset for actual battery systems and the rapidly changing costs, it is not clear how different battery projections should be weighted. For example, should projections published in 2018 be given higher weight than those published in 2016? Or are some organizations better at making projections and therefore should be given higher weight?

In the interest of providing a neutral survey of the current literature, all cost projections included in this report are weighted equally. Only storage projections published in 2017 or later were considered. Many of the newest projections, however, are simply a compilation of older projections (just like this report). For example, Comello and Reichelstein (2019) relies on publications produced in 2017 or earlier, and Nian, Jindal, an Li (2019) use Cole et al. (2016) and IRENA (2017) for their cost projections. Thus, many of the latest papers with cost projections would create known redundancies (per the second challenge listed above) and were therefore excluded from this work. All cost values were converted to $2019 \$$ using the consumer pricing index. In cases where the dollar year was not specified, the dollar year was assumed to be the same as the publication year.

We only used projections for 4-hour lithium-ion storage systems. We define the 4-hour duration as the output duration of the battery, such that a 4-hour device would be able to discharge at rated power capacity for 4-hours. In practice that would mean that the device would charge for more than 4 hours and would nominally hold more than its rated energy capacity in order to compensate for losses during charge and discharge.

We report our price projections as a total system overnight capital cost expressed in units of $\$ / \mathrm{kWh}$. However, not all components of the battery system cost scale directly with the energy capacity (i.e., kWh) of the system (Feldman et al. Forthcoming). For example, the inverter costs scale according to the power capacity (i.e., $\mathrm{kW}$ ) of the system, and some cost components such as the developer costs can scale with both power and energy. By expressing battery costs in $\$ / \mathrm{kWh}$, we are deviating from other power generation technologies such as combustion turbines or solar photovoltaic plants where capital costs are usually expressed as $\$ / \mathrm{kW}$. We use the units of $\$ / \mathrm{kWh}$ because that is the most common way that battery system costs have been expressed in published material to date. The $\$ / \mathrm{kWh}$ costs we report can be converted to $\$ / \mathrm{kW}$ costs simply by multiplying by the duration (e.g., a $\$ 300 / \mathrm{kWh}$, 4-hour battery would have a power capacity cost of $\$ 1200 / \mathrm{kW})$.

To develop cost projections, storage costs were normalized to their 2019 value such that each projection started with a value of 1 in 2019. We chose to use normalized costs rather than absolute costs because systems were not always clearly defined in the publications. For example, it is not clear if a system is more expensive because it is more efficient and has a longer lifetime, 
or if the authors simply anticipate higher system costs. With the normalized method, many of the difference matter to a lesser degree. Additionally, as will be shown in the results section, the 2019 benchmark cost that we have chosen for our current cost of storage is lower than nearly all the 2019 costs for projections published in 2017. By using normalized costs, we can more easily use these 2017 projections to inform cost reductions from our lower initial point.

If a publication began its projections after 2019, the 2019 value was estimated using linear extrapolation from the nearest value. For example, if the 2020 price was $\$ 500 / \mathrm{kWh}$ and the 2021 price was $\$ 480 / \mathrm{kWh}$, then the 2019 price was assumed to be $\$ 520 / \mathrm{kWh}$. Because projections tend to have more rapid declines in the early years, the linear approach will tend to underestimate the 2019 value, which in turn will overestimate the normalized values. If publications only provided values for specific years (e.g., 2018, 2020, and 2030), linear interpolation was used to fill in values for in-between years in order to create yearly projections. ${ }^{1}$

In order to define our low, mid, and high projections, we only considered cost projections published in 2018 and later. Projections published in 2017 are still shown in many figures in the results section, and we used the 2017-vintage data as a benchmark for the projections that we developed. We felt that the later vintage publications would provide a better assessment on anticipated storage cost reductions than those published in earlier years.

We defined our low, mid, and high projections as the minimum, median, and maximum point, respectively in 2020,2025, and 2030. Defining the 2050 points was more challenging because only four datasets extended to 2050 . Of the three datasets, they showed a $19 \%, 25 \%, 27 \%$, and $39 \%$ cost reduction from 2030 to 2050 . The 39\% reduction was used from the low case, while $25 \%$ was used for the mid and high cases. In other words, the low case was assumed to decline by $39 \%$ from 2030 to 2050 , while the mid and high cases were assumed to decline by $25 \%$ from 2030 to 2050 .

Points in between 2018, 2020, 2025, 2030, and 2050 were set based on linear interpolation between years with values assigned. To convert these normalized low, mid, and high projections into cost values, the normalized values were multiplied by the 4-hour battery storage cost from Feldman et al. (Forthcoming) to produce 4-hour battery systems costs.

To estimate the costs for other storage durations (i.e., durations other than 4 hours), we assign separate energy costs and power costs such that

$$
\text { Total Cost }(\$ / \mathrm{kWh})=\text { Energy Cost }(\$ / \mathrm{kWh})+\text { Power Cost }(\$ / \mathrm{kW}) / \text { Duration }(\mathrm{hr})
$$

To break apart the total cost into energy and power components, we used the 4-hour and 2-hour cost estimates from Feldman et al. (Forthcoming). By using the total cost for two distinct durations, we could calculate the energy and power costs. We could also check these energy and power costs against the 1-hour and 0.5-hour cost estimates that were also included in Feldman et

\footnotetext{
${ }^{1}$ There was one exception to this linear interpolation. Because the projection from Schmidt et al. (2019) drove some of the low-cost projection in this work, we interpolated their values using a fourth-order polynomial in order to get a better estimates for their pre-2035 values.
} 
al. (Forthcoming). We assume that the relative cost reductions developed for the total battery system cost apply equally to the energy and power components of the battery.

The method employed in this work relies solely on literature projections. It does not take into account other factors that might impact costs over time, such as materials availability, market size, and policy factors. Unless these and other factors are not captured in the work surveyed, then they will not be reflected in the projection produced here.

\section{Results and Discussion}

The normalized cost trajectories with the low, mid, and high projections are shown in Figure 1. The high projection follows the highest cost trajectory (of 2018 vintage or newer) through 2030. It then receives the $25 \%$ cost reduction from 2030 through 2050 as described in the methods section. The mid and low projections have initial slopes being steeper than later slopes, indicating that most publications see larger cost reductions in the near-term that then slow over time. By 2030 , costs are reduced by $63 \%, 47 \%$, and $26 \%$ in the low, mid, and high cases, respectively, and by 2050 are reduced by $78 \%, 60 \%$, and $44 \%$, respectively. 

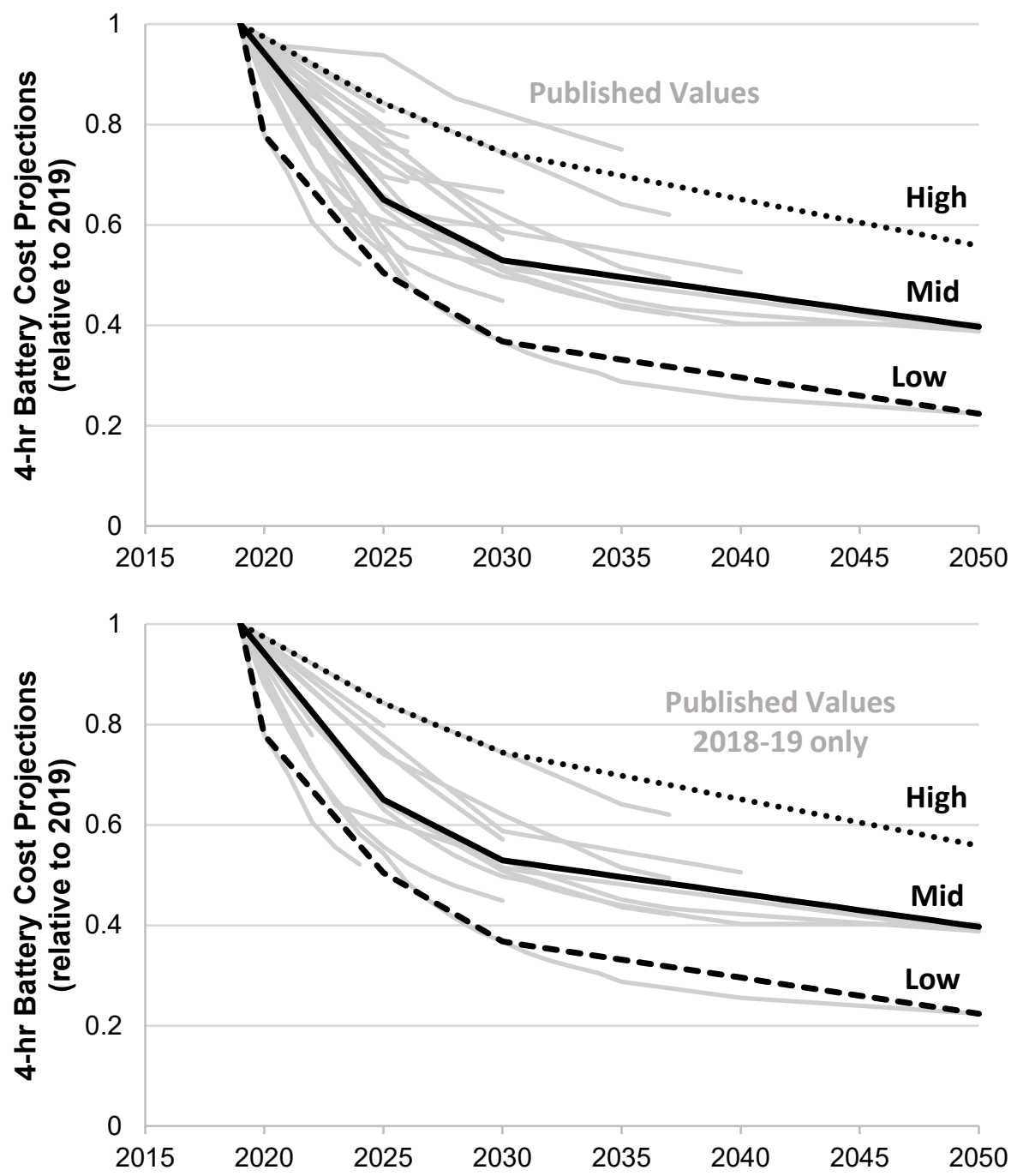

Figure 1. Battery cost projections for 4-hour lithium-ion systems, with values relative to 2019 . The high, mid, and low cost projections developed in this work are shown as the bolded lines. The upper figure shows the full range of cost projections used in this work, while the lower figure shows only those cost projections published after 2017. Figure values are included in the Appendix.

The resulting total system cost for a 4-hour device is shown in Figure 2. The 2019 starting point of $\$ 380 / \mathrm{kWh}$ is taken from Feldman et al. (Forthcoming). Although there is uncertainty in the 2019 cost (which is discussed later), we use a single cost for 2019 for convenience as we apply these costs in our long-term planning models (applying the same costs in 2019 means that the 2019 solution will not change as we shift from a "high" to a "mid" to a "low" cost projection for storage). By definition, the projections follow the same trajectories as the normalized cost values. Storage costs are $\$ 124 / \mathrm{kWh}, \$ 207 / \mathrm{kWh}$, and $\$ 338 / \mathrm{kWh}$ in 2030 and $\$ 76 / \mathrm{kWh}, \$ 156 / \mathrm{kWh}$, and $\$ 258 / \mathrm{kWh}$ in 2050 . Costs for each year and each trajectory are included in the Appendix. 


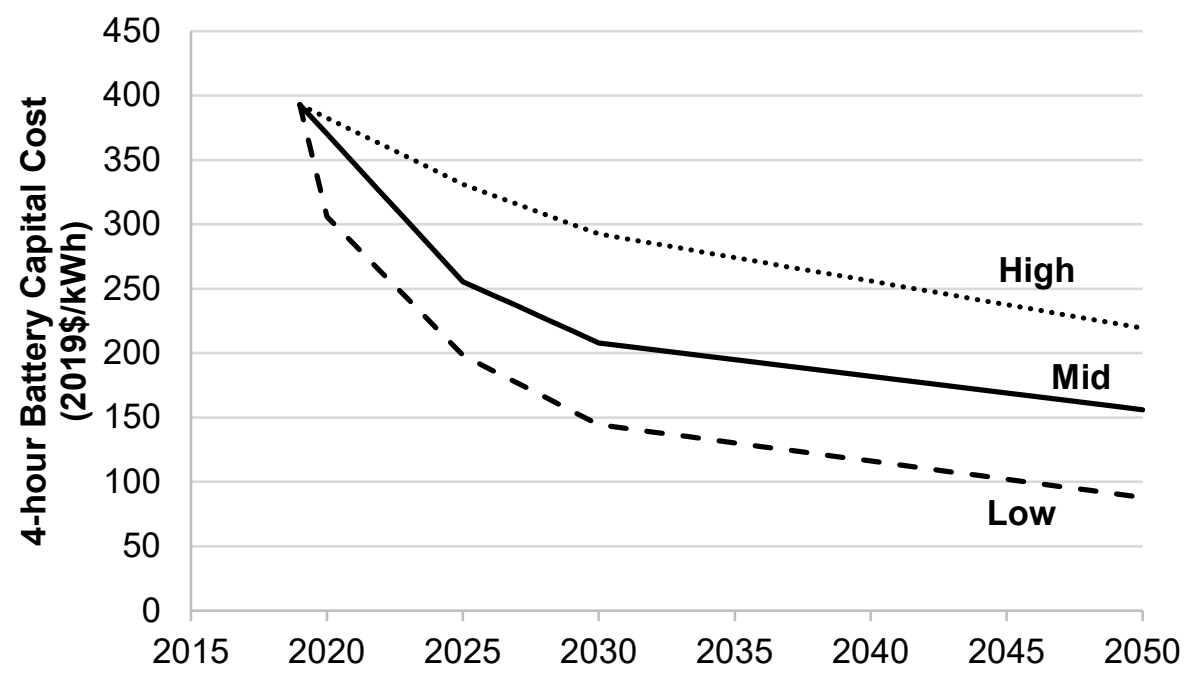

Figure 2. Battery cost projections for 4-hour lithium ion systems.

These values represent overnight capital costs for the complete battery system. Figure values are included in the Appendix.

Figure 3 shows how the absolute cost projections from Figure 2 compare to the published cost projection values. Because we chose to develop our projections based on the normalized cost values, they do not necessarily line up with the published cost projections. Many of the published cost projections never even reach the starting point that we have selected, while a few others are at some point lower than our low projection. Some of that discrepancy is due to the vintage of the projection. Cost projections published in 2017 tend to be higher than those published in 2018 or later. The lower plot in Figure 3 shows that the cost projections tend to be better aligned on an absolute basis when only the more recent cost projections are considered. 

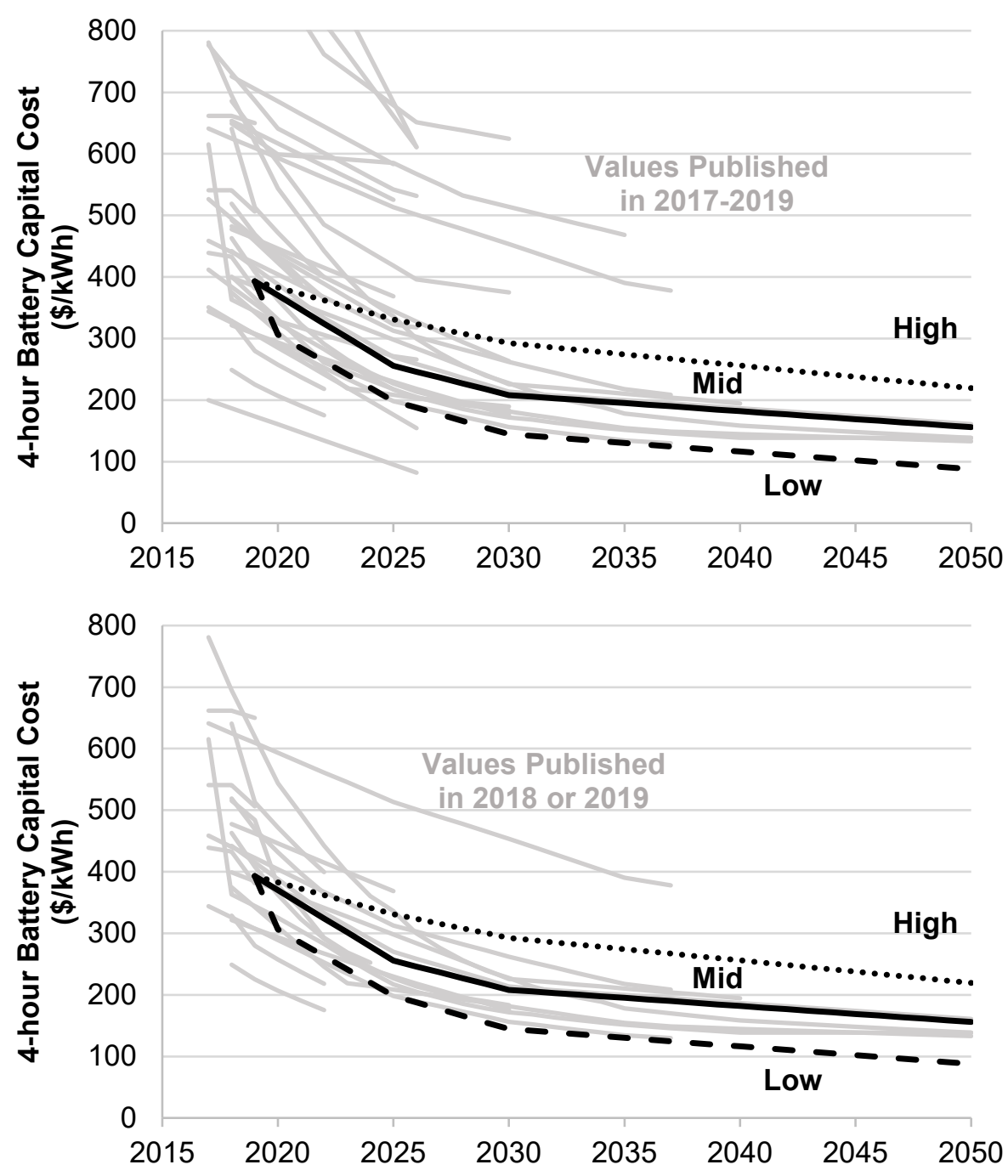

Figure 3. Battery cost projections developed in this work (bolded lines) relative to published cost projections. The upper figure shows the full range of cost projections used in this work, while the lower figure shows only those cost projections published after 2017. Cost values above $\$ 800 / \mathrm{kWh}$ are not shown.

One of the key assumptions in our projections is the choice of the starting point. A higher or lower starting point would shift the set of projections up or down relative to the change in magnitude of the starting point. To better assess the quality of our starting point, we compared the value from Feldman et al. (Forthcoming) with other values published in 2018 or later (shown in Figure 4). We did not consider older reported values because of the rapid changes in battery costs. This comparison increases our confidence that the starting value we have selected is reasonable, although it does demonstrate that there is considerable uncertainty $( \pm \$ 100 / \mathrm{kWh})$ in the current price of battery storage systems. 


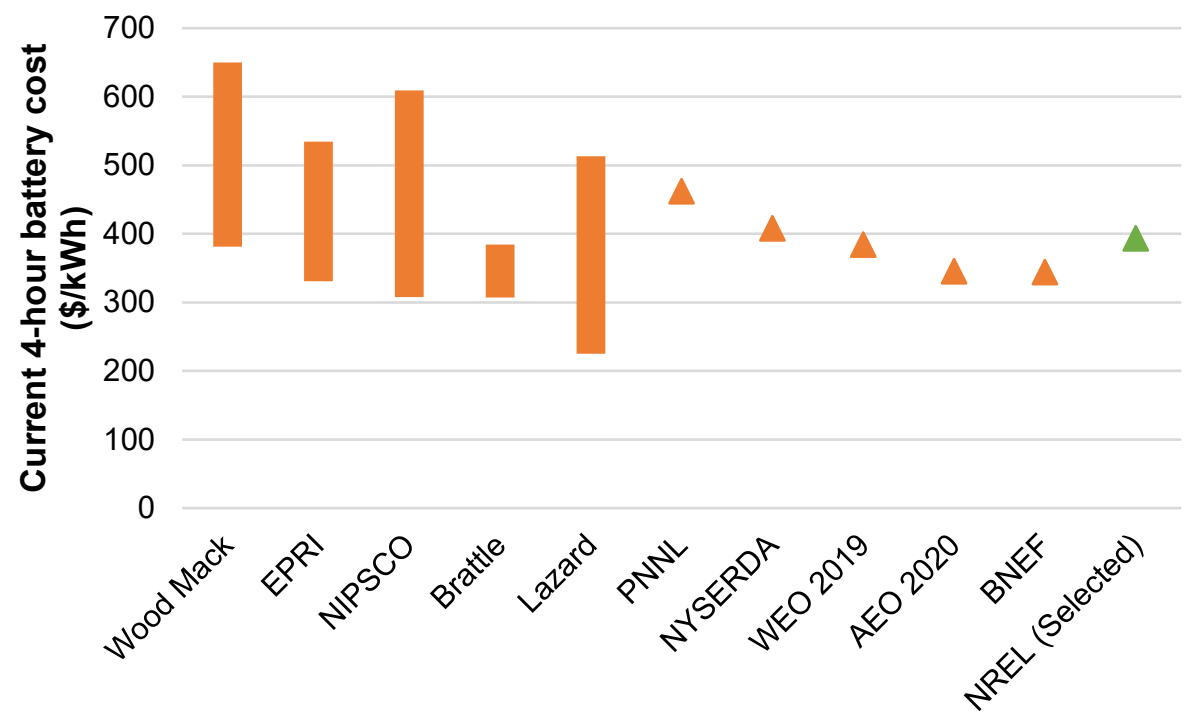

Figure 4. Current battery storage costs from studies published in 2018 or later. The NREL value (Feldman et al. Forthcoming) was selected as the 2019 starting cost for this work.

One of the other challenges with using the normalized cost reductions to develop our projections is that projections that start at a higher value than our starting point might see greater cost reduction potential, and thus have a high percent reduction but still never have a low $\$ / \mathrm{kWh}$ cost. Conversely, projections that start lower than our starting point might have smaller cost reduction potential on a percentage basis but achieve very low $\$ / \mathrm{kWh}$ costs. However, we still prefer to use the normalized cost reduction numbers because of the large discrepancy in starting costs across published projections, and because it helps to obviate the challenge of different cost and system definitions in the different publications.

Figure 5 shows the cost projections for the power and energy components of the battery. The breakdown of power and energy is derived from Feldman et al. (Forthcoming) as described in the methods section. These components are combined to give a total system cost, where the system cost (in $\$ / \mathrm{kWh}$ ) is the power component divided by the duration plus the energy component. 

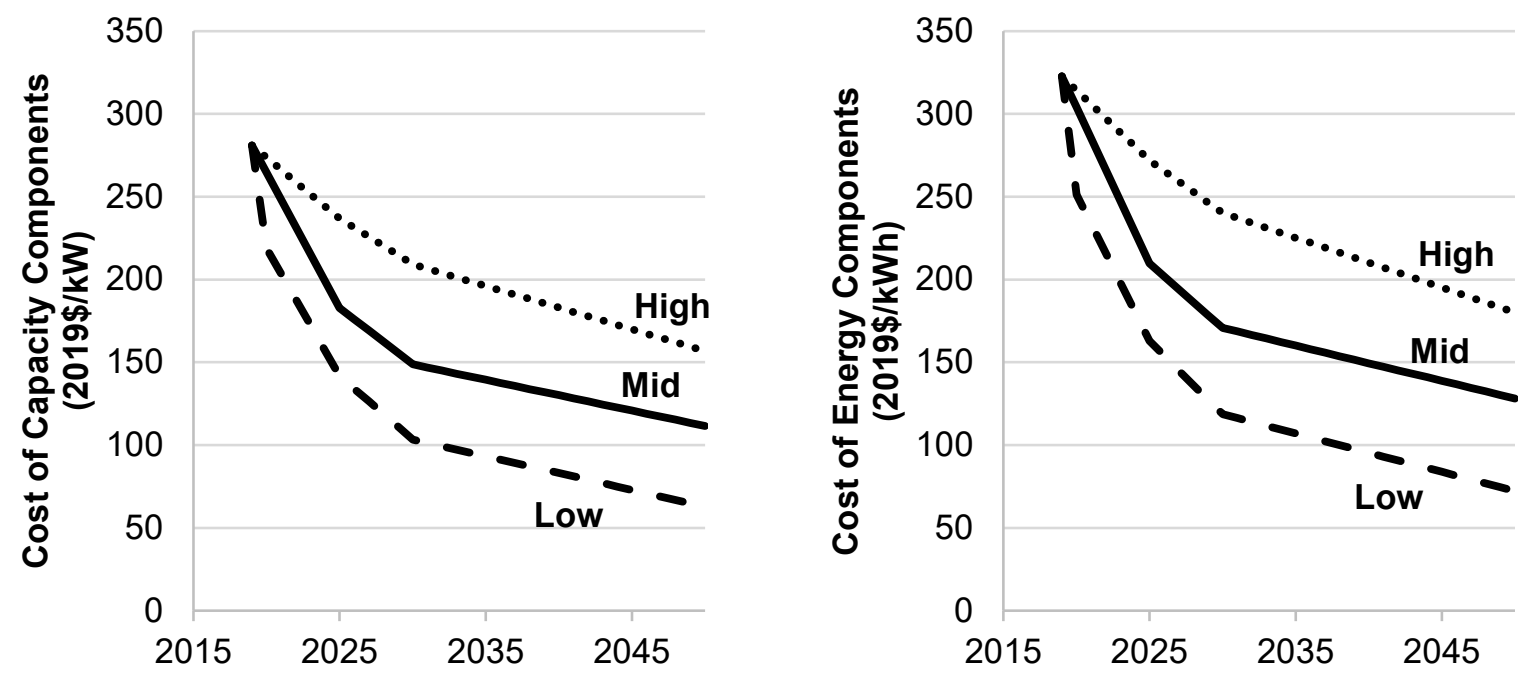

Figure 5. Cost projections for power (left) and energy (right) components of lithium-ion systems. Note the different units in the two plots.

These power and energy costs can be used to specify the capital costs for other durations. Figure 6 shows the cost projections for 2-, 4-, and 6-hour duration batteries (using the mid projection only). On a $\$ / \mathrm{kWh}$ basis, longer duration batteries have a lower capital cost, and on a $\$ / \mathrm{kW}$ basis, shorter duration batteries have a lower capital cost. Figure 6 (left) also demonstrates why it is critical to cite the duration whenever providing a capital cost in $\$ / \mathrm{kWh}$ or $\$ / \mathrm{kW}$.
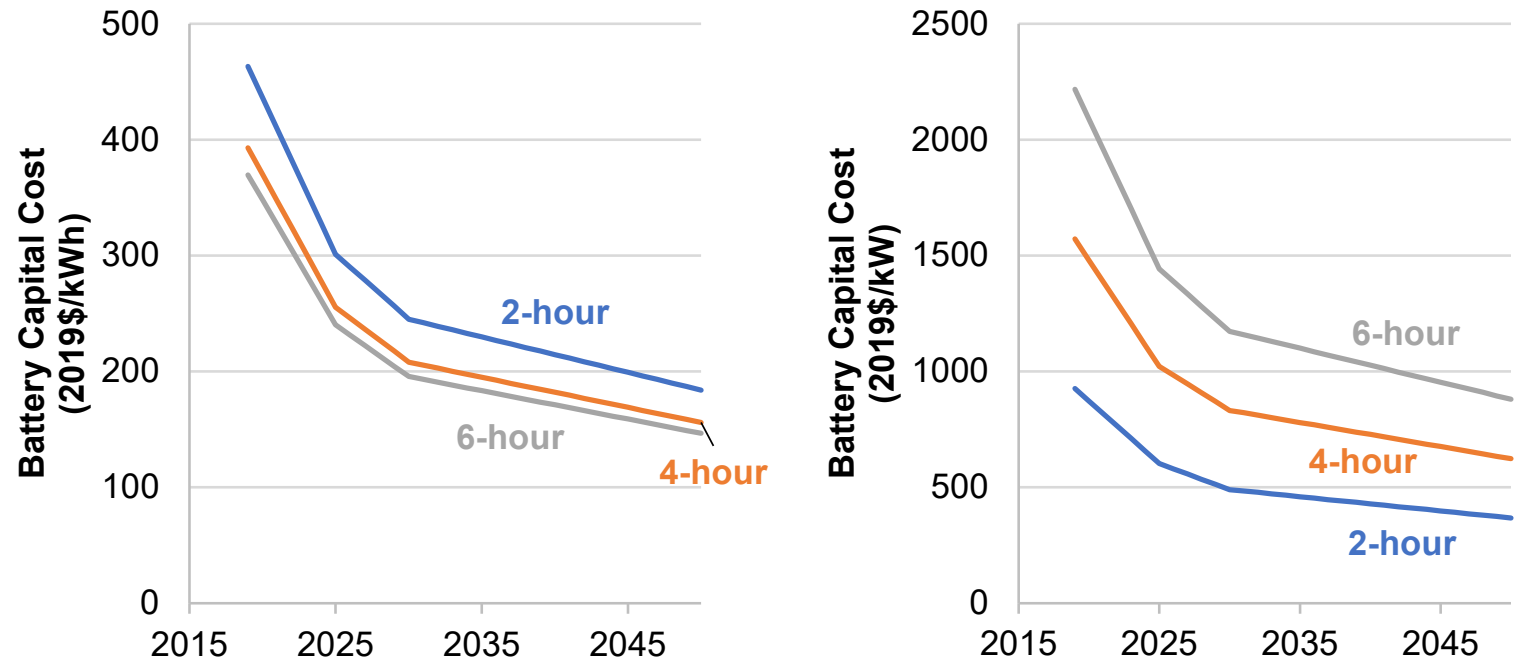

Figure 6. Cost projections for 2-, 4-, and 6-hour duration batteries using the mid cost projection. Left shows the values in $\$ / k W h$, while right shows the costs in $\$ / k W$.

To fully specify the cost and performance of a battery storage system for capacity expansion modeling tools, additional parameters besides the capital costs are needed. Figure 6 shows the range of variable operations and maintenance (VOM), fixed operations and maintenance (FOM), 
lifetime, and round-trip efficiency ${ }^{2}$ assumptions from the publications surveyed. The rightmost point in the figure shows the value that we have selected to represent our 4-hour battery system. The VOM is generally taken to be zero or near zero, and we have adopted zero for the VOM. This VOM is defined to coincide with an assumed one cycle per day and a given calendar lifetime. Cycling more than once per day might reduce that lifetime, so cycles beyond once per day should see a non-zero VOM.

We have allocated the all operating costs (at the one-cycle-per-day level) to the FOM. By putting the operations and maintenance costs in the FOM rather than the VOM we in essence assume that battery performance has been guaranteed over the lifetime, such that operating the battery does not incur any costs to the battery operator. The FOM has a much broader range of values. One of the primary differences in the level of FOM was whether augmentation or performance maintenance were included in the cost. For example, DNV GL (2017) reports a $\$ 6 / \mathrm{kW}-\mathrm{yr}$ FOM and a $\$ 7.5 / \mathrm{kWh}-\mathrm{yr}$ capacity maintenance cost to address degradation (values in $2017 \$$ ). Lower FOM numbers typically include only simple maintenance while higher FOM numbers include some capacity additions or replacements to deal with degradation. We have adopted a FOM value from the high end and assume that the FOM cost will counteract degradation such that the system will be able to perform at rated capacity throughout its lifetime. The FOM value selected is $2.5 \%$ of the $\$ / \mathrm{kW}$ capacity cost for a 4-hour battery. We assume that this FOM is consistent with providing approximately one cycle per day. If the battery is operating at a much higher rate of cycling, then this FOM value might not be sufficient to counteract degradation.

\footnotetext{
${ }^{2}$ Round-trip efficiency is defined as the system efficiency through a charge/discharge cycle. For example, it would include losses associated with cooling systems or battery control equipment.
} 

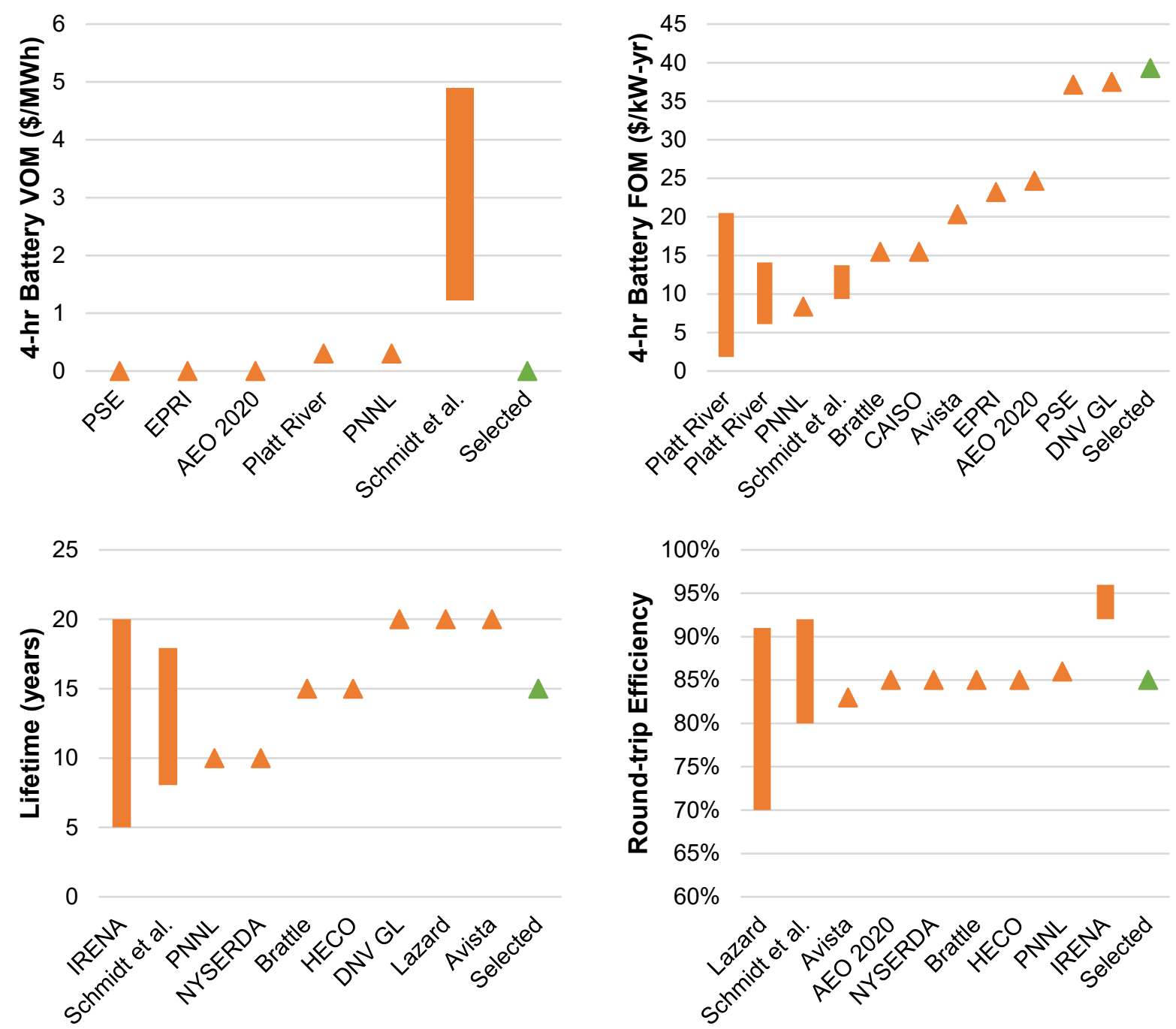

Figure 7. Variable O\&M (top right), fixed O\&M (top left), lifetime (bottom right), and round-trip efficiency (bottom left) from various published sources. The values selected for this study are the rightmost values shown.

The lifetime we selected is 15 years, which is near the median of the published values. The round-trip efficiency is chosen to be $85 \%$, which is well aligned with published values.

\section{Summary}

Battery storage costs have evolved rapidly over the past several years, necessitating an update to storage cost projections used in long-term planning models and other activities. This work documents the development of these projections, which are based on recent publications of storage costs. The projections show a wide range of storage costs, both in terms of current costs as well as future costs. Although the range in projections is considerable, all projections do show a decline in capital costs, with cost reductions by 2025 of $6-48 \%$.

The cost projections developed in this work utilize the normalized cost reductions across the literature, and result in 26-63\% capital cost reductions by 2030 and $44-78 \%$ cost reductions by 
2050. The cost projections are also accompanied by assumed operations and maintenance costs, lifetimes, and round-trip efficiencies, and these performance metrics are benchmarked against other published values.

\section{References}

Aquino, Todd, Mathew Roling, Chris Baker, and Lukas Rowland. 2017. "Battery Energy Storage Technology Assessment.” https://www.prpa.org/wp-content/uploads/2017/10/HDRBattery-Energy-Storage-Assessment.pdf.

Avista. 2017. "2017 Electric Integrated Resource Plan.” AVISTA. https:/www.myavista.com//media/myavista/content-documents/about-us/our-company/irp-documents/2017-electricirp-final.pdf?la=en.

BNEF. 2019. "Long-Term Energy Storage Outlook."

Cohen, Stuart, Jonathon Becker, David A. Bielen, Maxwell Brown, Wesley J. Cole, Kelly P. Eurek, Allister Frazier, et al. 2019. "Regional Energy Deployment System (ReEDS) Model Documentation: Version 2018.” NREL/TP-6A20-72023. Golden, CO: National Renewable Energy Laboratory. https://doi.org/10.2172/1505935.

Cole, Wesley, and Will A. Frazier. 2019. "Cost Projections for Utility-Scale Battery Storage." Technical Report NREL/TP-6A20-73222. Golden, CO: National Renewable Energy Laboratory. https://doi.org/10.2172/1529218.

Cole, Wesley, Cara Marcy, Venkat Krishnan, and Robert Margolis. 2016. "Utility-Scale Lithium-Ion Storage Cost Projections for Use in Capacity Expansion Models." In 2016 North American Power Symposium (NAPS), 1-6. Denver, CO, United States: IEEE. https://doi.org/10.1109/NAPS.2016.7747866.

Comello, Stephen, and Stefan Reichelstein. 2019. "The Emergence of Cost Effective Battery Storage.” Nature Communications 10 (1): 1-9. https://doi.org/10.1038/s41467-01909988-z.

DNV GL. 2017. "Energy Storage Potential Evaluation.” 10046409-R-01-E. https://www.pacificpower.net/content/dam/pacific_power/doc/About_Us/Rates_Regulati on/Oregon/Regulatory_Filings/Docket_UM_1857/7-14-

17_Filing/report/exhibits/Appendix_A_REDACTED.pdf.

EIA. 2020. "Annual Energy Outlook 2020 with Projections to 2050." AEO2020. Annual Energy

Outlook. Washington, D.C.: U.S. Energy Information Administration.

https://www.eia.gov/outlooks/aeo/pdf/AEO2019.pdf.

Energy and Environmental Economics. 2017. "RESOLVE Documentation: CPUC 2017 IRP:

Inputs \& Assumptions.” Energy and Environmental Economics, Inc.

http://cpuc.ca.gov/uploadedFiles/CPUCWebsite/Content/UtilitiesIndustries/Energy/Energ yPrograms/ElectPowerProcurementGeneration/irp/AttachmentB.RESOLVE_Inputs_Ass umptions_2017-09-15.pdf.

EPRI. 2018. "Energy Storage Technology and Cost Assessment: Executive Summary.” 3002013958.

https:/www.epri.com/\#/pages/product/000000003002013958/\&src=mail?lang=en-US.

Feldman, David, Ran Fu, Ashwin Ramdas, Jal Desai, and Robert Margolis. Forthcoming. "U.S. Solar Photovoltaic System and Energy Storage Cost Benchmark: Q1 2019." NREL/TP6A20-75161. Golden, CO: National Renewable Energy Laboratory. 
Hledik, Ryan, Judy Chang, Roger Lueken, Johannes Pfeifenberger, John Imon Pedtke, and Jeremy Vollen. 2018. "The Economic Potential for Energy Storage in Nevada," October, 92.

IEA. 2019. "World Energy Outlook 2019.” International Energy Agency.

IRENA. 2017. "Electricity Storage and Renewables: Costs and Markets to 2030." https://www.irena.org/publications/2017/Oct/Electricity-storage-and-renewables-costsand-markets.

Lazard. 2018. "Lazard's Levelized Cost of Storage Analysis-Version 4.0." https://www.lazard.com/media/450774/lazards-levelized-cost-of-storage-version-40vfinal.pdf.

—. 2019. "Lazard's Levelized Cost of Storage Analysis_-Version 5.0." https://www.lazard.com/media/451087/lazards-levelized-cost-of-storage-version-50vf.pdf.

Mai, Trieu, Easan Drury, Kelly Eurek, Natalie Bodington, Anthony Lopez, and Andrew Perry. 2013. "Resource Planning Model: An Integrated Resource Planning and Dispatch Tool for Regional Electric Systems.” TP-6A20-56723. National Renewable Energy Laboratory. http://www.nrel.gov/docs/fy13osti/56723.pdf.

Mongird, K, V Viswanathan, P Balducci, J Alam, V Fotedar, V Koritarov, and B Hadjerioua. 2019. "Energy Storage Technology and Cost Characterization Report.” PNNL-28866. Richland, WA: Pacific Northwest National Laboratory. https://www.energy.gov/sites/prod/files/2019/07/f65/Storage\%20Cost\%20and\%20Perfor mance\%20Characterization\%20Report_Final.pdf.

Navigant. 2017. "Storage in the Northwest." Presented at the Northwest Demand Response and Energy Storage Summit, Portland, OR, September 28.

Nian, Victor, Gautam Jindal, and Hailong Li. 2019. "A Feasibility Study on Integrating LargeScale Battery Energy Storage Systems with Combined Cycle Power Generation - Setting the Bottom Line." Energy 185 (October): 396-408. https://doi.org/10.1016/j.energy.2019.07.028.

NIPSCO. 2018. "NIPSCO Integrated Resource Plan 2018: Appendix A.” Northern Indiana Public Service Company LLC. https://www.nipsco.com/docs/librariesprovider11/ratesand-tariffs/irp/2018-nipsco-irp-appendix-a.pdf?sfvrsn=2.

NREL. 2019. “2019 Annual Technology Baseline.” Golden, CO: National Renewable Energy Laboratory. https://atb.nrel.gov/.

NYSERDA. 2018. "New York State Energy Storage Roadmap." New York State Energy Research and Development Authority. http://documents.dps.ny.gov/public/Common/ViewDoc.aspx?DocRefId=\{2A1BFBC985B4-4DAE-BCAE-164B21B0DC3D\}.

Puget Sound Energy. 2017. "2017 PSE Integrated Resource Plan." https://www.pse.com/pages/energy-supply/resource-planning.

Schmidt, Oliver, Sylvain Melchior, Adam Hawkes, and Iain Staffell. 2019. "Projecting the Future Levelized Cost of Electricity Storage Technologies." Joule, January. https://doi.org/10.1016/j.joule.2018.12.008.

Wood Mackenzie \& ESA. 2019. "U.S. Energy Storage Monitor: Q4 2018." 


\section{Appendix}

Table 2 includes the values that are plotted in Figure 1 and Figure 2. Figure 9 and Figure 10 show the comparison of the projections developed in this work relative to the projections that were produced in last year's report (Cole and Frazier 2019). Although 4-hour costs did not change much from last year's report, the relative distribution between the power and energy costs did change. Thus, 2-hour or 6-hour battery costs calculated using data from this year's report will show greater differences than the 4-hour batteries.

Table 2. Values from Figure 1 and Figure 2, which show the normalized and absolute storage costs over time. Storage costs are overnight capital costs for a complete 4-hour battery system.

\begin{tabular}{|l|l|l|l|l|l|l|}
\hline & \multicolumn{3}{|c|}{ Normalized Cost Reduction } & \multicolumn{3}{|c|}{ 4-hour Storage Costs } \\
\hline Year & Low & Mid & High & Low & Mid & High \\
\hline $\mathbf{2 0 1 9}$ & 1.00 & 1.00 & 1.00 & 393 & 393 & 393 \\
\hline $\mathbf{2 0 2 0}$ & 0.78 & 0.94 & 0.97 & 306 & 370 & 383 \\
\hline $\mathbf{2 0 2 1}$ & 0.73 & 0.89 & 0.95 & 286 & 351 & 372 \\
\hline $\mathbf{2 0 2 2}$ & 0.68 & 0.84 & 0.92 & 266 & 331 & 362 \\
\hline $\mathbf{2 0 2 3}$ & 0.62 & 0.79 & 0.90 & 245 & 312 & 352 \\
\hline $\mathbf{2 0 2 4}$ & 0.57 & 0.74 & 0.87 & 225 & 293 & 341 \\
\hline $\mathbf{2 0 2 5}$ & 0.52 & 0.70 & 0.84 & 205 & 273 & 331 \\
\hline $\mathbf{2 0 2 6}$ & 0.49 & 0.66 & 0.82 & 193 & 260 & 323 \\
\hline $\mathbf{2 0 2 7}$ & 0.46 & 0.63 & 0.80 & 181 & 247 & 316 \\
\hline $\mathbf{2 0 2 8}$ & 0.43 & 0.60 & 0.78 & 169 & 234 & 308 \\
\hline $\mathbf{2 0 2 9}$ & 0.40 & 0.56 & 0.76 & 156 & 221 & 300 \\
\hline $\mathbf{2 0 3 0}$ & 0.37 & 0.53 & 0.74 & 144 & 208 & 293 \\
\hline $\mathbf{2 0 3 1}$ & 0.36 & 0.52 & 0.74 & 142 & 205 & 289 \\
\hline $\mathbf{2 0 3 2}$ & 0.35 & 0.52 & 0.73 & 139 & 203 & 285 \\
\hline $\mathbf{2 0 3 3}$ & 0.35 & 0.51 & 0.72 & 136 & 200 & 282 \\
\hline $\mathbf{2 0 3 4}$ & 0.34 & 0.50 & 0.71 & 133 & 198 & 278 \\
\hline $\mathbf{2 0 3 5}$ & 0.33 & 0.50 & 0.70 & 130 & 195 & 274 \\
\hline $\mathbf{2 0 3 6}$ & 0.32 & 0.49 & 0.69 & 127 & 192 & 271 \\
\hline $\mathbf{2 0 3 7}$ & 0.32 & 0.48 & 0.68 & 125 & 190 & 267 \\
\hline $\mathbf{2 0 3 8}$ & 0.31 & 0.48 & 0.67 & 122 & 187 & 263 \\
\hline $\mathbf{2 0 3 9}$ & 0.30 & 0.47 & 0.66 & 119 & 185 & 260 \\
\hline $\mathbf{2 0 4 0}$ & 0.30 & 0.46 & 0.65 & 116 & 182 & 256 \\
\hline $\mathbf{2 0 4 1}$ & 0.29 & 0.46 & 0.64 & 113 & 179 & 252 \\
\hline $\mathbf{2 0 4 2}$ & 0.28 & 0.45 & 0.63 & 111 & 177 & 249 \\
\hline $\mathbf{2 0 4 3}$ & 0.27 & 0.44 & 0.62 & 108 & 174 & 245 \\
\hline $\mathbf{2 0 4 4}$ & 0.27 & 0.44 & 0.61 & 105 & 172 & 241 \\
\hline $\mathbf{2 0 4 5}$ & 0.26 & 0.43 & 0.60 & 102 & 169 & 238 \\
\hline $\mathbf{2 0 4 6}$ & 0.25 & 0.42 & 0.60 & 99 & 166 & 234 \\
\hline $\mathbf{2 0 4 7}$ & 0.25 & 0.42 & 0.59 & 96 & 164 & 230 \\
\hline & & & & & & \\
\hline
\end{tabular}




\begin{tabular}{|c|c|c|c|c|c|c|}
\hline \multirow[b]{2}{*}{2048} & \multicolumn{3}{|c|}{ Normalized Cost Reduction } & \multicolumn{3}{|c|}{$\begin{array}{c}\text { 4-hour Storage Costs } \\
(2019 \$ / \mathrm{kWh})\end{array}$} \\
\hline & 0.24 & 0.41 & 0.58 & 94 & 161 & 227 \\
\hline 2049 & 0.23 & 0.40 & 0.57 & 91 & 159 & 223 \\
\hline 2050 & 0.22 & 0.40 & 0.56 & 88 & 156 & 219 \\
\hline
\end{tabular}

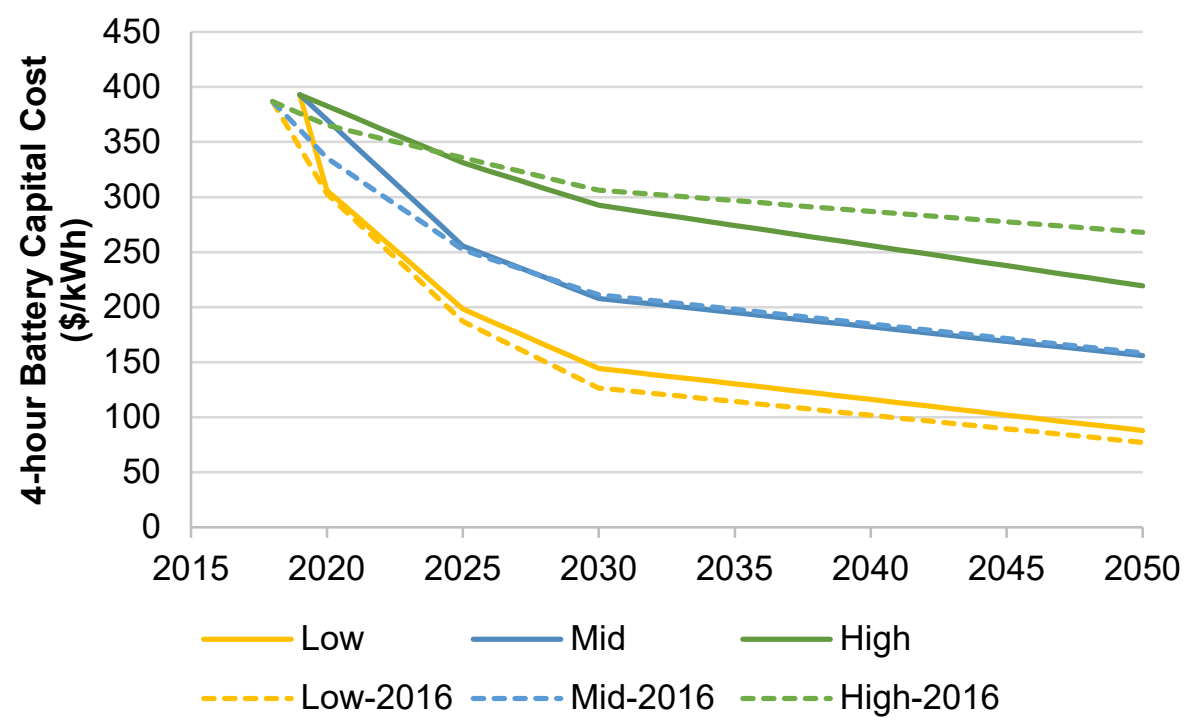

Figure 8. Comparison of cost projections developed in this report (solid lines) against the values from the 2019 cost projection report (Cole and Frazier 2019) (dashed lines).

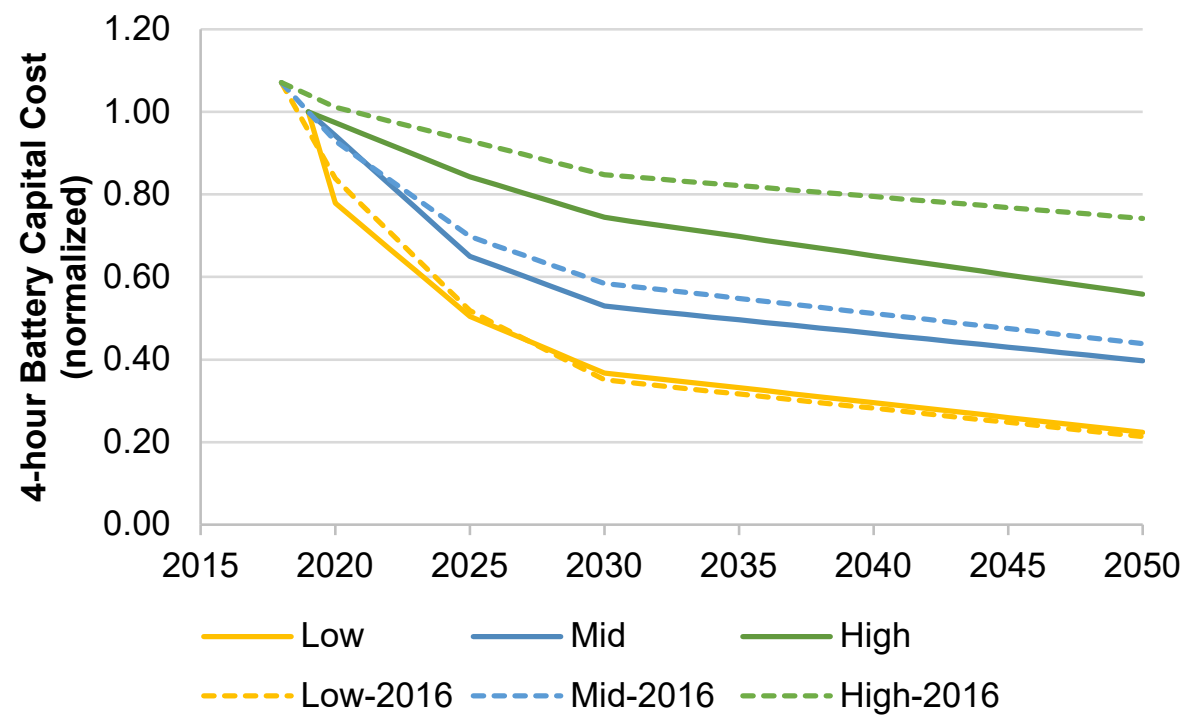

Figure 9. Comparison of cost projections developed in this report (solid lines) the values from the 2019 cost projection report (Cole and Frazier 2019) (dashed lines), with all values normalized to the "Mid" cost projection in the year 2019. 